\title{
Assessing the value of increasing GB interconnection
}

\author{
Waqquas Bukhsh, Callum MacIver, Keith Bell \\ Institute of Energy and Environment, \\ University of Strathclyde, Glasgow, United Kingdom. \\ \{waqquas.bukhsh, callum.maciver, keith.bell\}@strath.ac.uk
}

\begin{abstract}
The liberalisation of electricity markets and increasing penetration of renewable generation are encouraging trading opportunities to be identified and developed. In Europe, the importance of interconnection is well recognised. Interconnections are particularly important for islanded nations, like Great Britain, which provides access to generation and demand across the national boundaries via sub-sea HVDC cables while providing means to share reserves enhancing the security of supply and reducing overall costs. There are plans in place to significantly increase the current $5 \mathrm{GW}$ of interconnection capacity between GB and neighbouring European countries. The paper investigates the expected impacts that a large increase in interconnection capacity could have on key electricity market parameters such as marginal prices, carbon emissions and the nature of utilisation of existing and future GB interconnections. Several scenarios have been considered to model future uncertainty for the years 2020 and 2025.
\end{abstract}

Index Terms-HVDC interconnection ; linear programming; European electricity markets; security of electricity supply; decarbonisation of electricity system; uncertainty quantification.

\section{INTRODUCTION}

The interconnection of electricity markets is considered a key component to unlock the potential of renewable generation in Europe. Several European scale case studies have demonstrated that increasing interconnection capacity can enhance security of supply, increase overall social welfare and help achieve decarbonisation targets through optimal utilisation of installed renewable generation [1], [2]. For the aforementioned reasons, the European Commission (EC) has been promoting the development of interconnections in parallel to market liberalisation and has set an ambitious target of $15 \%$ import capacity as compared to the installed generation capacity for all member countries by 2030 [3].

For island nations like Great Britain (GB), meeting these interconnection targets entails the use of long-distance HVDC subsea transmission technology to enable cross border power flows. Currently, the GB electricity system has an interconnection capacity of $5 \mathrm{GW}$ (4 GW to mainland Europe and $1 \mathrm{GW}$ to the island of Ireland). There are

The research leading to these results has received funding from the Engineering and Physical Sciences Research Council under grant number EP/R021333/1. plans to increase current GB interconnection capacity by approximately $150 \%$ by the mid-2020's with new interconnection projects under development with France, Ireland, Norway and Denmark [4]. Given such a large potential increase in the GB interconnection capacity, the following key questions arise:

- What impact will future GB interconnection have on GB electricity prices?

- What impact will new GB interconnection have on the nature of the utilisation of existing and future GB interconnection projects?

- What role will new interconnection investments play in the decarbonisation of the GB and European electricity system?

This paper aims to address the above questions whilst considering credible GB interconnection scenarios. To investigate the impact of increasing GB interconnection on electricity prices and carbon emissions, a modelling framework is required that can adequately model the behaviours of Europe wide electricity transmission system. It is also important to model the spatial and temporal variation of renewable sources and the transmission constraints that exists between various electricity markets in the European electricity system.

The academic literature focusing on the impact of future GB interconnection is sparse. In [5], a regression model is used to study the impact of adding extra interconnection capacity between France and Great Britain. This approach relies on historic data of flows between France and GB and does not consider other GB interconnection or power exchanges between other European countries. An approximate load flow model of the European interconnected system is presented in [6], which make use of publicly available data of trades between countries. The methods based on historic data provide good approximations on flows and trades for a given topology but does not provide accurate results on the impact of new investments. Impact of selected new interconnection investments is presented in [7]. The results demonstrate that new interconnection investments increase overall welfare and reduce carbon emissions.

In this paper, a European scale transmission system model is proposed that models the behaviour of a coupled 
European electricity market. Each European country is represented by a single node and constraints are imposed on the maximum net transfer capacity (NTC) of electricity trades that can take place between connected countries.

The proposed model is tested on a range of GB interconnection scenarios and for the generation background scenarios for the years 2020 and 2025. The generation and demand scenarios are obtained from the ENTSO-e Ten Year Network Development Plan [1]. The benefits of each scenario are quantified in terms of its impact on the marginal price, reduction in overall carbon emissions and facilitation of the renewable generation resources.

Furthermore, the paper highlights the importance of modelling interconnection losses and proposes a way to capture it using equivalent hurdle costs. It is demonstrated that without using hurdle costs or appropriate interconnection losses, the interconnection utilisation is overestimated and may lead to erroneous conclusions.

The main contributions of this paper are as follows:

- use of a European transmission system model which is spatially diverse (30 European countries with NTCs) and temporally detailed (1-year of operation with hourly resolution) to quantify the impact of new GB interconnection;

- assessment of the impact of new GB interconnection considering a range of future GB interconnection capacity scenarios

- highlighting the importance of modelling interconnection losses for assessing the value of future interconnections.

The rest of the paper is organised as follows. Section II provides a brief description of the modelling framework. Section III provides a discussion on scenarios for the year 2020 and 2025. The results for all the scenarios are presented and discussed in Section IV and the paper concludes with conclusions and discussion in Section V.

\section{MOdelling FRAMEWORK}

A European scale electricity dispatch model is used to determine hourly expected imports/exports to the GB system. The electricity dispatch model is built using a platform provided by the French transmission system operator (RTE) called ANTARES [8]. A particular feature of this platform is its modelling of the hydro resources: reservoir, run of the river and pumped storage. The penetration of renewable generation is modelled using historic data. The overall mathematical formulation takes the form of a unit commitment problem with weekly blocks that are coupled by the constraints on reservoir capacities [9]. Some important features of the European dispatch model are discussed in the following subsections.

\section{A. The spatial and temporal scale of the model}

Figure 1 shows the spatial scale of the model: each country is represented by a single node (except for Denmark and United Kingdom which are split into two nodes,

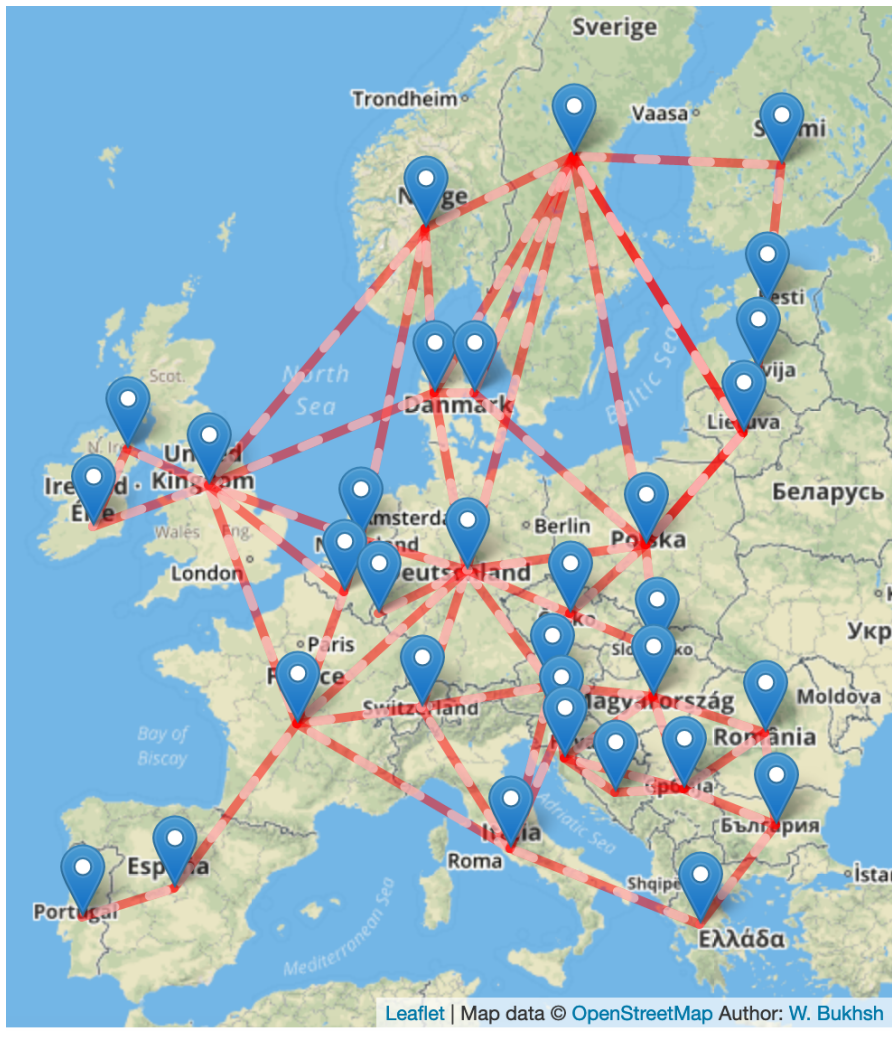

Fig. 1. A representative European electricity transmission network. Each country is represented by a single node (except for the UK and Denmark, which are represented by two nodes, respectively) and the Net Transfer Capacities (NTCs) are used to model the interconnection limits between the countries. Data for the European network is obtained from the Ten Year Network Development Plan (TYNP) of ENTSO-e.

respectively). The to and from net transfer capacities (NTCs) between the countries are obtained from the 2018 Ten Year Network Development Plan (TYNDP) of ENTSO-e [1].

The European dispatch model is simulated for 1-year with a time resolution of 1 -hour. This time resolution requires hourly time-series of input parameters like demand and available renewable generation as well as information on the availability of hydro resources and the planned and unplanned outage rates of the fossil fuel generation. This is used alongside assumptions on the market bid price of different generation types to determine the lowest overall cost hourly dispatch of generation.

\section{B. Generation and demand data}

The generation capacities and demand data are obtained from the TYNDP, which provides best estimates for the generation capacities in each country for 2020 and 2025. The generation types represented in the European dispatch model are presented in Table I alongside the assumed plant efficiency and $\mathrm{CO}_{2}$ contribution by generation type.

The data available through TYNDP of ENTSO-e report a single number for gas generation capacity and does not differentiate between different levels of efficiency that the gas generation units may have in each European country. 
TABLE I

GENERATION TYPES REPRESENTED IN THE EUROPEAN DISPATCH MODEL.

\begin{tabular}{lcc}
\hline Type & $\begin{array}{c}\text { CO2 Emission } \\
(\mathrm{kg} / \mathrm{GJ})\end{array}$ & $\begin{array}{c}\text { Efficiency } \\
\%\end{array}$ \\
\hline Biofuels & 0 & 40 \\
Gas - Low & 57 & 44 \\
Gas - Med & 57 & 52 \\
Gas - High & 57 & 58 \\
Hard Coal & 94 & 40 \\
Lignite & 101 & 40 \\
Nuclear & 0 & 33 \\
Oil & 100 & 35 \\
CHP & 57 & 58 \\
Other RES & 0 & 40 \\
Other NonRes & 100 & 35 \\
\hline
\end{tabular}

TABLE II

PLANNED AND COMMISSIONED INTERCONNECTION TO GB.

\begin{tabular}{|c|c|c|c|c|c|}
\hline & Name & Country & $\begin{array}{c}\text { Capacity } \\
(\mathrm{GW})\end{array}$ & $\begin{array}{c}\text { Length } \\
(\mathrm{km})\end{array}$ & $\begin{array}{c}\text { Loss } \\
(\%)\end{array}$ \\
\hline \multirow{5}{*}{ مُ } & IFA & France & 2.0 & 73 & 2.34 \\
\hline & Moyle & N. Ireland & 0.5 & 64 & 2.36 \\
\hline & BritNed & Netherlands & 1.0 & 259 & 3.00 \\
\hline & EWIC & Ireland & 0.5 & 262 & 4.68 \\
\hline & NEMO & Belgium & 1.0 & 140 & 2.60 \\
\hline \multirow{6}{*}{ 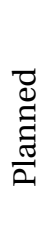 } & Eleclink & France & 1.0 & 51 & 2.50 \\
\hline & IFA2 & France & 1.0 & 240 & 3.03 \\
\hline & NSL & Norway & 1.4 & 730 & 4.92 \\
\hline & GreenLink & Ireland & 0.5 & 160 & 2.64 \\
\hline & FABLink & France & 1.4 & 220 & 2.88 \\
\hline & VikingLink & Denmark & 1.4 & 760 & 5.04 \\
\hline
\end{tabular}

To model this, the gas generation capacity is split into three categories of high, medium and low efficiency, as shown in Table I.

\section{Modelling of HVDC and HVAC losses}

Losses are an inevitable consequence of transporting power from generation to demand. In this work, losses are split into two categories: transmission losses within the HVAC system and interconnection losses on HVDC links. In Europe, the transmission losses in the HVAC system are typically in the order of $2 \%$ [10]. In this work, the demand in each country is increased by $2 \%$ to represent the losses within the system.

HVDC losses are modelled for the GB links using a loss factor. The loss factors applied to GB interconnection projects are presented in Table II using either publicly stated or estimated percentage loss figures. The estimated losses on an HVDC link depend on various factors including the length of the link, the type of HVDC technology used (LCC or VSC), and the system voltage.

\section{Modelling of generation planned and forced outages}

Planned and forced outages of generating units are modelled using the reliability statistics provided by ENTSOe for each generation type. Planned outages in Europe normally occur outwith the winter months to avoid plant shutdowns when the demand for electricity is high. To model this, forced outages are assigned randomly across the year whereas planned outages are given a lower probability of occurring over winter months.

\section{E. Modelling of renewable generation}

Wind and solar generation are modelled as input hourly time series in ANTARES. The profiles used are based on the historical weather year of 2007 as obtained from renewables ninja [11], [12]. This aligns with the demand year from which ENTSO-E derives its future demand time-series estimates. The profiles are scaled in line with the estimated capacity in each scenario year with the solar generation being modelled as a fixed generation infeed to the system, while wind generation can be curtailed at a price.

\section{F. Modelling of hydro generation}

Hydro generation is split into three categories: run-ofriver (ROR), pumped storage and reservoir storage. Historic data on realised hydro generation in each European country is used alongside knowledge of the capacity of each type within each country to model the three hydro generation types. The ROR is modelled as a fixed generation for every hour in a month but output varies across each month to reflect the changing flow rate in the rivers over the year. Pumped storage is controllable and the optimisation decides on the amount that is pumped or discharged from pumped storage facilities in each country. The hydro generation from the reservoirs are scheduled weekly using ANTARES' in-built heuristic method, with a monthly constraint on availability [8].

\section{G. Assumptions regarding the fuel costs and UK Carbon Price Support}

The marginal cost of a generator depends on a number of things: fuel cost, plant efficiency, start-up cost, shut-down cost and cost of $\mathrm{CO} 2$ emissions per MWh. The data for these parameters are taken from the TYNDP report [1]. In reality, the price offered by the fossil fuel generators varies based on the location and over time due to changes in the global fuel prices. To approximate this, a stochastic daily price modulation of $\pm 2 \%$ is applied to all thermal generation to reflect locational price variations while a $\pm 5 \%$ variation on the central marginal cost assumption is applied linearly across the year to reflect higher winter and lower summer fuel prices.

The fossil fuel electricity producers in the UK pay an additional tax which is called UK Carbon Price Support (CPS) [13]. Currently, the CPS is $£ 18 /$ ton of carbon emissions. The CPS is imposed in the model for the 2020 scenario, which makes UK fossil fuel generation more 
expensive than the equivalent mainland European generation which is subject only to a carbon price set by the EU Emmissions Trading Scheme (EU-ETS). The baseline assumption is that the CPS is likely to be removed and carbon prices across Europe levelised for 2025 scenarios, however, in this paper, the results are provided with and without the UK Carbon Price Support for the year 2025.

\section{SCENARIOS FOR 2020 AND 2025}

A set of scenarios is developed to model the uncertainty in the future generation mix and GB interconnection capacity. The scenarios for the generation mix are taken from the ENTSO-e TYNDP [1] for the year 2020 and 2025. The interconnection scenarios are developed following consultation with industry and experts about the plausible GB interconnection that can be expected to come online in the coming years.

The results presented in this paper are for the scenarios developed for the years 2020 and 2025. The TYNDP of ENTSO-e provides a single scenario for generation background for the years 2020 and 2025. This data is used along with a set of GB interconnection scenarios for the two years. For the year 2025, the results are presented for two different carbon price scenarios of Coal before Gas (CBG) and Gas before Coal (GBC). The merit-order switch of coal and gas is modelled using an assumed EU-ETS carbon price of $30 € /$ tonCo2e for $\mathrm{CBG}$ and $60 € /$ tonCo2e for $\mathrm{GBC}$, respectively.

Table II presents the existing and planned GB interconnection projects considered in this paper. The subsea HVDC interconnection projects have long time-scales, are very expensive and are subject to a range of uncertainties that could delay or in some cases cancel the project altogether. In this context, it is important to capture the uncertainty in the realisation of such interconnection projects. Figures 2 presents GB interconnection scenarios for the years 2020 and 2025. Five interconnection scenarios are considered for the year 2020 that range from $5 \mathrm{GW}$ to 8.4 GW of interconnection capacity. Eight interconnection scenarios are constructed for the year 2025, with a base case capacity estimate of $8.4 \mathrm{GW}$ and a maximum of $13.1 \mathrm{GW}$.

\section{RESUlTs}

The proposed framework of quantifying the impact of increased interconnection is demonstrated for the years 2020 and 2025. The results for the two years are presented in the following subsections.

\section{A. Results for the year 2020}

Figure 3 presents the impact of increasing GB interconnection on average GB marginal price and carbon emissions. It can be noted that the average GB marginal price reduces with increasing GB interconnection capacity. This is due to an increase in GB imports which displace expensive thermal generation within GB. The best-fit regression line presented in Figure 3(a) has a negative gradient of 0.5 ,

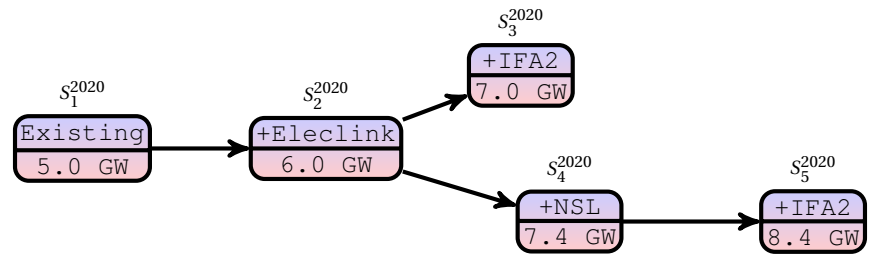

(a) Five interconnection scenarios for the year 2020. The scenario tree starts with the existing GB interconnection capacity of $5.0 \mathrm{GW}$.

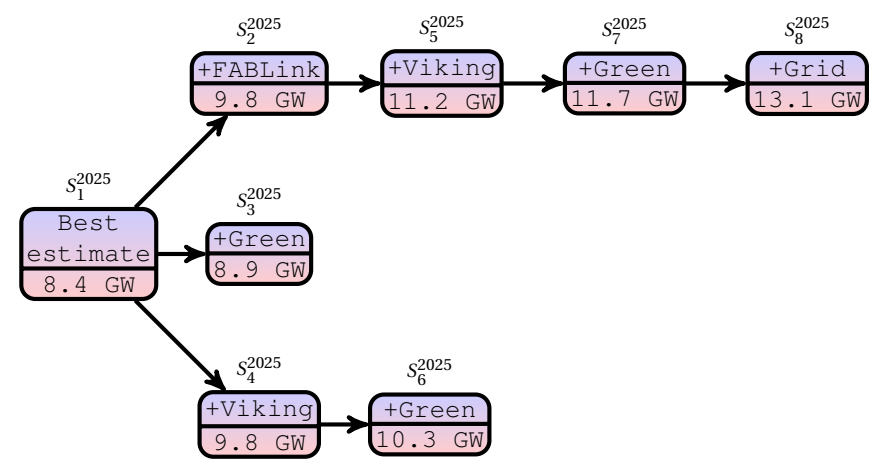

(b) Eight interconnection scenarios for the year 2025. The scenario tree starts with the best estimate for GB interconnection capacity of $8.4 \mathrm{GW}$. Fig. 2. Two set of GB interconnection scenarios for the year 2020 and 2025 .

which means that increasing GB interconnection capacity by $1 \mathrm{GW}$ decreases the average marginal price in GB by $0.5 € /$ MWh.

Figure 3(b) presents the incremental impact of increasing GB interconnection on GB and European carbon emissions. A negative value in the graph means that the carbon emissions have decreased as compared to the previous scenario. It can be seen that the GB carbon emissions improve significantly with increasing GB interconnection, signifying a large reduction in the use of fossil fuel plant in GB. However, the results show that this is not reflected through to overall European carbon emissions which remain relatively unchanged by new GB interconnection, with only small net carbon reductions observed for additional interconnections to France. Indeed, in moving from scenario 2 to scenario 4, the total emissions actually rise with the introduction of a link to Norway. This can be explained by the fact that the reduction in GB fossil fuel is made possible by greater imports from neighbouring countries. While the displaced generation in GB is dominated by gas, the additional imports from other European countries are facilitated by increases in for example hydro and nuclear power in directly connected countries but also by a partial increase in the use of fossil fuel generation across several countries. Some of this is contributed by heavily polluting lignite and coal plants, particularly in countries like Germany and the Czech Republic with the net impact being that emissions reductions in GB are largely counterbalanced and in some instances even surpassed by emissions increases elsewhere.

Figure 4 presents the impact of increasing GB interconnections on the utilisation of the existing links and the 


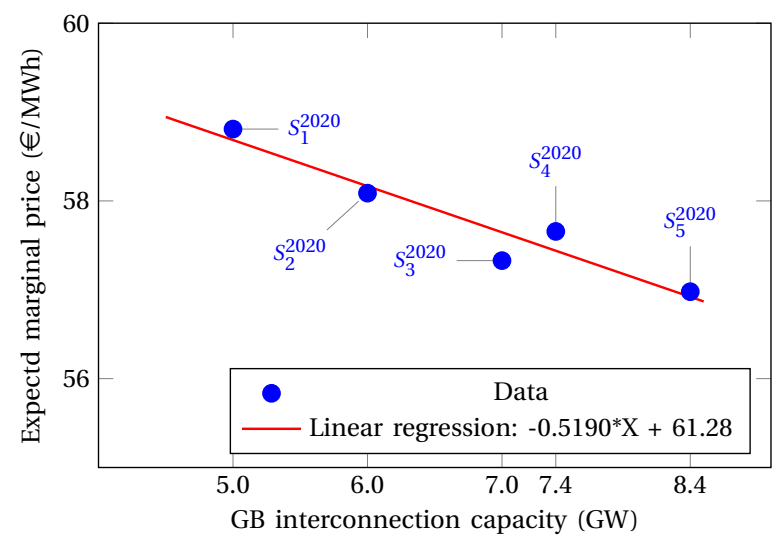

(a) Average GB marginal price for the 5 interconnection scenarios. Red line is the best fit line that shows the decreasing trend of the GB marginal price.

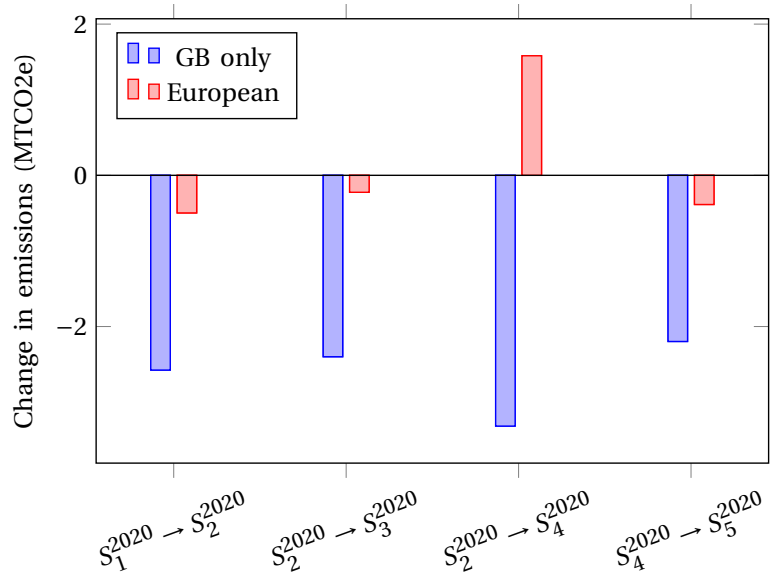

(b) Impact of GB interconnection on carbon emissions. The impact is calculated as an incremental change of adding an extra GB interconnector. Negative value means decrease in carbon emissions.

Fig. 3. Impact of increasing GB interconnection on GB marginal price and the carbon emissions.

average absolute price difference between the neighbouring electricity markets. It can be noted that the absolute price difference and the utilisation of the links decrease as capacity increases. In Figure 4(a) the average price difference between GB and France is approximately $15 € / M W h$ and utilisation of the link is $96 \%$. The next scenario adds 1 GW of additional capacity between GB and France, which reduces the average price difference between the two countries to $12 € / \mathrm{MWh}$ and also marginally decreases the utilisation to $95 \%$. The third scenario models additional 1 GW capacity between GB and France and with this link the average marginal price decreases to $11 € / \mathrm{MWh}$ and the utilisation of the link decreases to $94 \%$. The price difference of $11 € / \mathrm{MWh}$ is still high and it is higher than all other price differences shown in Figure 4(c). Due to this high price difference between GB and France, additional interconnection capacity does not dramatically decrease the utilisation of existing GB-France links.

The link to Norway NSL comes online in scenario 4 . The average price difference between Norway and GB decreases by $1 € /$ MWh between scenario 1 and scenario 3 . This is because of the convergence of marginal prices across Europe due to increasing GB interconnection. In scenario 4, with 1.4 GW interconnection capacity added between Norway and $\mathrm{GB}$, the average marginal price difference is $9.3 € / \mathrm{MWh}$ with $84 \%$ utilisation representing a $1.4 € / \mathrm{MWh}$ convergence in average marginal price. Scenario 5 models 1 GW link to France coming online after NSL and it reduces NSL utilisation by $1 \%$.

New interconnection investments impact the wider system prices as well. Overall, in all scenarios presented in Figure 4, it can be noted that average price differences were reasonably high and additional GB interconnection capacity did not significantly impact utilisation of the existing links.

\section{B. Results for the year 2025}

At the time of writing, electricity producers in the UK pay an additional tax called carbon price support (CPS) which is $£ 18 /$ ton $^{1}$ of carbon emission [13]. For the year 2025, the following four scenarios were considered:

- Gas before coal (GBC) without UK CPS

- Coal before gas (CBG) without UK CPS

- Gas before coal (GBC) with UK CPS

- Coal before gas (CBG) with UK CPS

Figure 5 presents the impact of increasing GB interconnection for the four chosen scenarios. In all four scenarios, the total change in average GB marginal price between all interconnection scenarios is within approximately $1 € / M W h$. This is a lower impact than seen in the 2020 results, suggesting a diminishing incremental influence of new interconnection capacity as total capacity rises. Figure 5(a) and Figure 5(b) presents average marginal prices for the two scenarios without UK Carbon Price Support. In these two cases, the GB generation prices are assumed to be equalised with European prices. This means that average GB prices are no longer significantly higher than most other neighbouring countries, as in the 2020 case, which means that there is a greater balance between imports and exports. While in importing periods GB marginal price will reduce on average due to interconnection providing access to cheaper generation in other markets, the opposite is true in exporting periods with GB marginal price being increased by interconnection facilitating increased access to market for more expensive local generation. Figure 5a shows that average prices remain relatively similar for all interconnector scenarios showing that the impact on prices of importing and exporting cases largely balance out in this scenario. Figure $5 \mathrm{~b}$ shows an increase in average marginal prices in the Gas before Coal scenario as new interconnection is added which suggests that exports increasingly dominate with the change in merit order making GB a

\footnotetext{
${ }^{1}$ UK Carbon Price Support of $£ 18 /$ ton is approximated to $€ 21 /$ ton for the analysis provided in this paper
} 

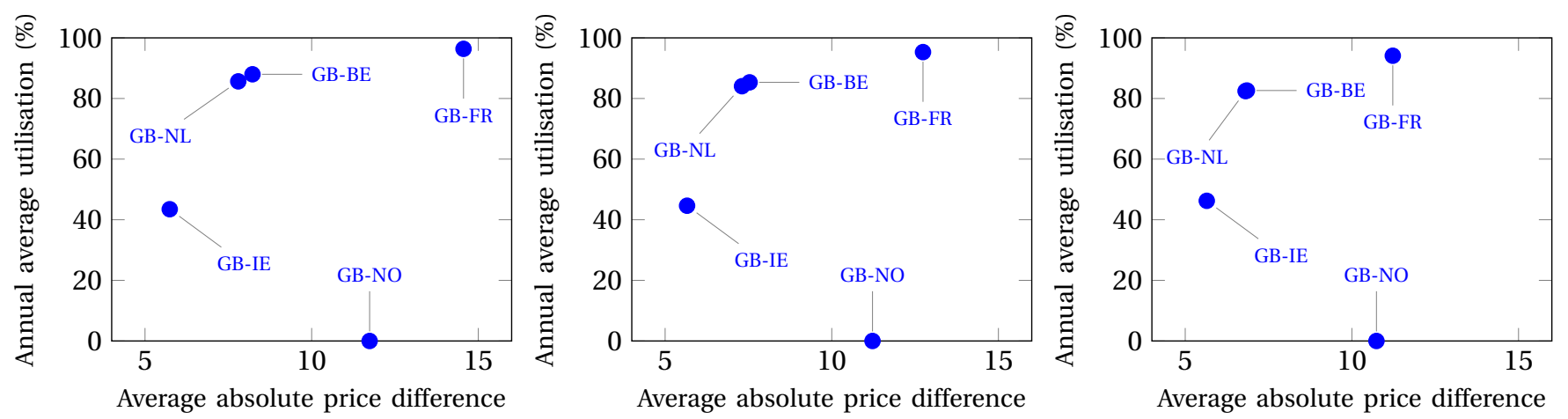

(a) $S_{1}^{2020}-5.0 \mathrm{GW}$ GB interconnection capacity

(b) $S_{2}^{2020}-6.0 \mathrm{GW}$ GB interconnection capacity

(c) $S_{3}^{2020}-7.0 \mathrm{GW}$ GB interconnection capacity

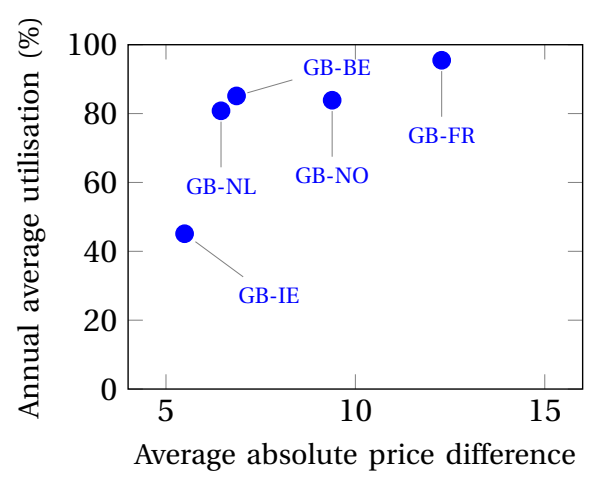

(d) $S_{4}^{2020}-7.4 \mathrm{GW}$ GB interconnection capacity

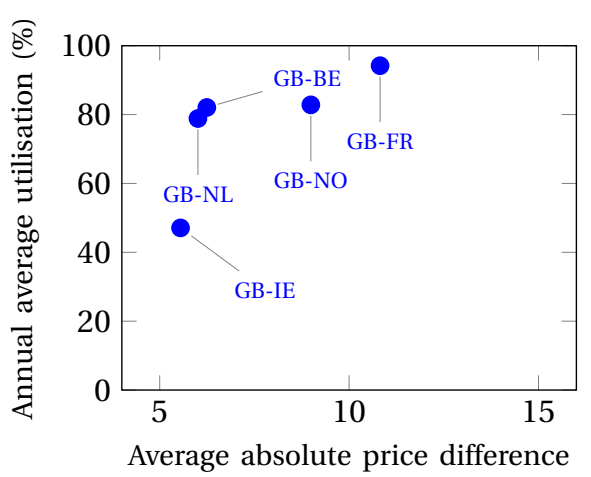

(e) $S_{5}^{2020}-8.4 \mathrm{GW}$ GB interconnection capacity

Fig. 4. Results showing the relationship between annual average absolute price difference and utilisation of selected GB interconnections for the five scenarios for the year 2020 .

relatively lower-priced market on average compared to its neighbours in this scenario.

Figure 5(c) and Figure 5(d) presents results for the case with UK Carbon Price Support still in place in the year 2025. In the Coal before Gas case (Figure 5(c)), the average GB marginal prices are higher than in the case without CPS included but the addition of interconnection again decreases prices from this higher base level. This shows that the reinstatement of the CPS changes the relative price of the GB market compared to its neighbours which return it to the status of being a predominantly importing market again, as in the 2020 case. In the Gas before Coal scenario including the CPS, (Figure 5(d)), it can be seen that the impact on GB average price varies depending on the type of interconnection investment. For example, increasing the interconnection to Ireland increases GB marginal prices because of increased exports to Ireland, whereas increasing interconnection to France decreases the GB marginal prices. Overall, in this scenario, the impact of various interconnection investments cancel out each others impact and the linear regression curve is close to a constant.

Due to the limited space in paper, the graphs of carbon emissions and impact on utilisation of interconnection for the year 2025 are not discussed in the paper. These are made available as a supplementary material here [14].

\section{Impact of modelling HVDC losses}

Modelling of losses over HVDC interconnection introduces a hurdle cost between connecting markets. it is important to capture this hurdle cost in the modelling to correctly quantify the utilisation and impact of an interconnector project. Some case studies in the literature have indeed used an assumption of lossless HVDC link e.g. in [15].

In this section, a case study is presented that demonstrates the importance of modelling HVDC losses. Scenario 5 of the year 2020 with $8.4 \mathrm{GW}$ of GB interconnection capacity is considered. In this scenario, there is $1.4 \mathrm{GW}$ of interconnection capacity between Norway and GB. The following four cases were simulated for the chosen scenario: (i) with $4.92 \%$ loss factor on the GB-Norway link, (ii) without any loss on the link, (iii) hurdle cost of $4.0 € /$ MWh on imports and exports, and (iv) hurdle cost of $2.5 € / \mathrm{MWh}$ on flows from GB to Norway and $2.9 € / M W h$ between Norway and GB, respectively. The choice of $4.0 € / M W h$ in case iii) is taken from [16] where the authors have used this hurdle cost for all interconnectors in their model. The asymmetric hurdle costs used in case iv) are derived by considering the loss factor and average price in each market with detailed explanation provided in Appendix A.

Figure 6 presents hourly flows between GB and Norway 


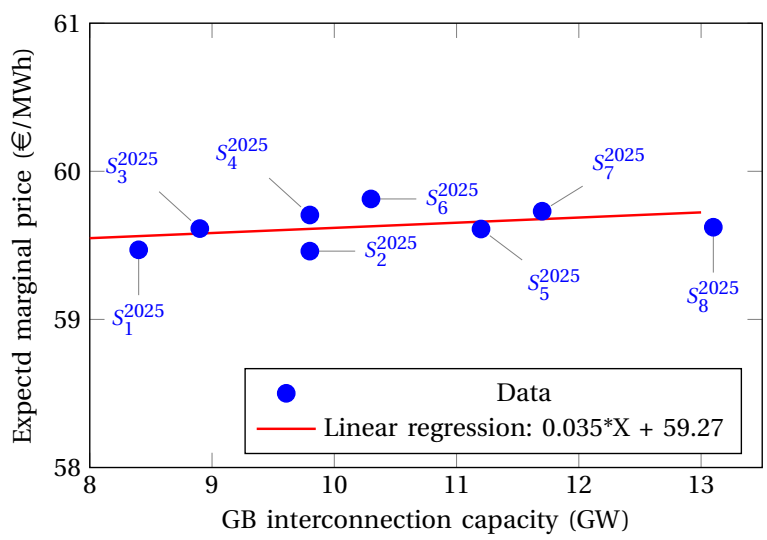

(a) 2025 Coal before Gas without UK Carbon Price Support

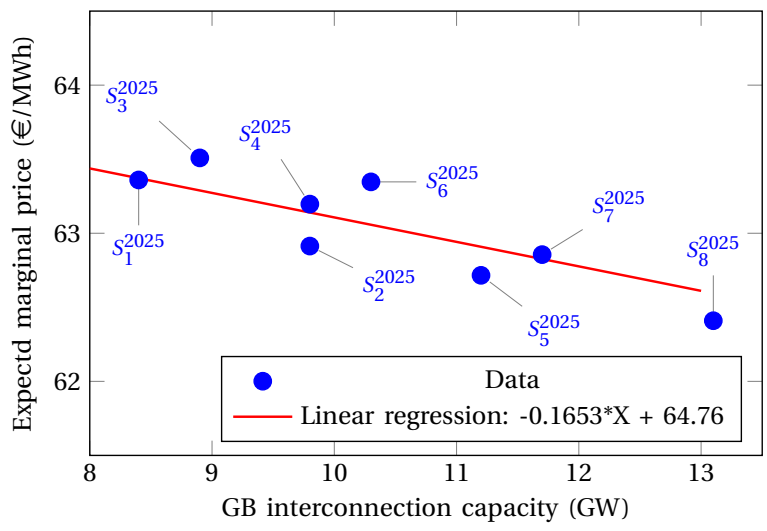

(c) 2025 Coal before Gas with UK Carbon Price Support

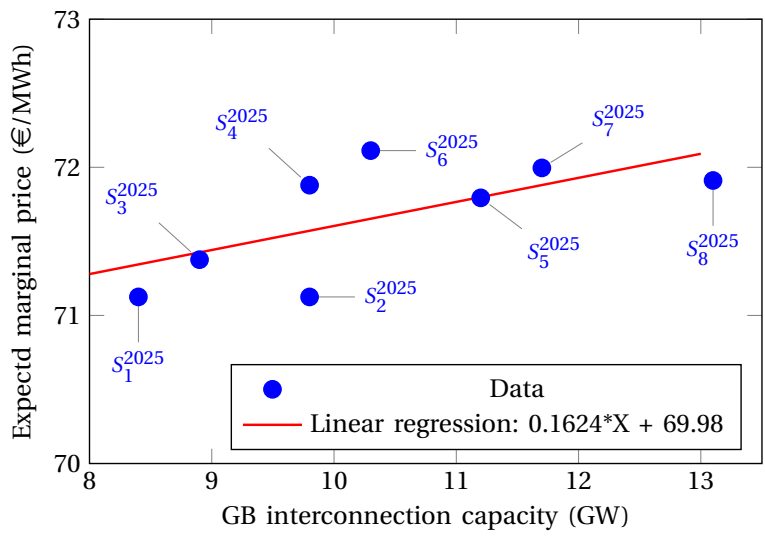

(b) 2025 Gas before Coal without UK Carbon Price Support

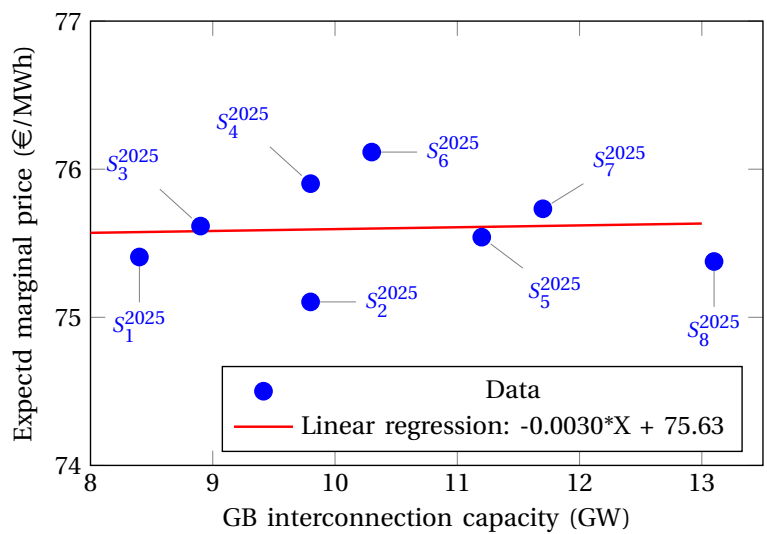

(d) 2025 Gas before Coal with UK Carbon Price Support

Fig. 5. Impact of increasing GB interconnection on GB marginal price. Four cases were considered - changing the merit order of coal and gas, and with and without consideration of UK Carbon Price Support.

for the four cases while Table III reports the average marginal prices in GB and Norway, GB imports, GB exports and utilisation of the link. In Figure 6 the $x$-axis represents the price difference between GB and Norway and the yaxis is the interconnection flows. The Figure shows that modelling of losses using a loss factor of $4.92 \%$ introduces a non-uniform hurdle cost between GB and Norway that is asymmetrical, approximately 3.0 €/MWh for GB imports and $1.0 € / \mathrm{MWh}$ for GB exports. In this case there was no interconnection flow between Norway and GB for $8.2 \%$ of the time (718 hours in a year) because the marginal price difference between the two countries in these hours is low enough that making a trade is not worth the losses encountered. Total utilisation in this case is $87.17 \%$, calculated as percentage of total annual absolute flows vs theoretical maximum absolute flows.

To show the value of modelling losses, case ii) shows that when you ignore the loss on the link, the modelled utilisation increases from $87.17 \%$ to $95.04 \%$ (Table III). This approach is likely to be least accurate with nonzero flow in all hours and the potential for significant overestimation of GB imports and exports through the link. With the hurdle cost of $4.0 €$, the model significantly underestimates the utilisation compared with the explicitly modelled losses case by $4.3 \%$. With the asymmetric hurdle cost based on the average prices of GB and NO, the model underestimates the utilisation of the link by just $0.8 \%$. This suggests the asymmetric hurdle costs of 2.5 and $2.9 € / \mathrm{MWh}$ are a good approximation of modelling the losses explicitly. However, as Figure 6 highlights there is a significant difference between the calculated hurdle costs and those implied from the explicit modelling of losses with apparently a slight underestimation of the GB import hurdle cost and an overestimation of the GB export hurdle costs. This means that flows in many hours are different under the two methods and suggests for greatest accuracy losses should be modelled explicitly.

\section{CONCLUSIONS AND Discussion}

In this paper, the application of a framework to assess the value of increasing interconnection capacity is presented. The proposed framework is demonstrated on increased GB interconnection capacity for the years 2020 and 2025 with a range of different interconnection and generation background scenarios. It is shown that increasing interconnection capacity has a positive impact on GB marginal prices for the year 2020 as it facilitates imports. Whereas in the year 2025, the impact is lower and largely dependent on 


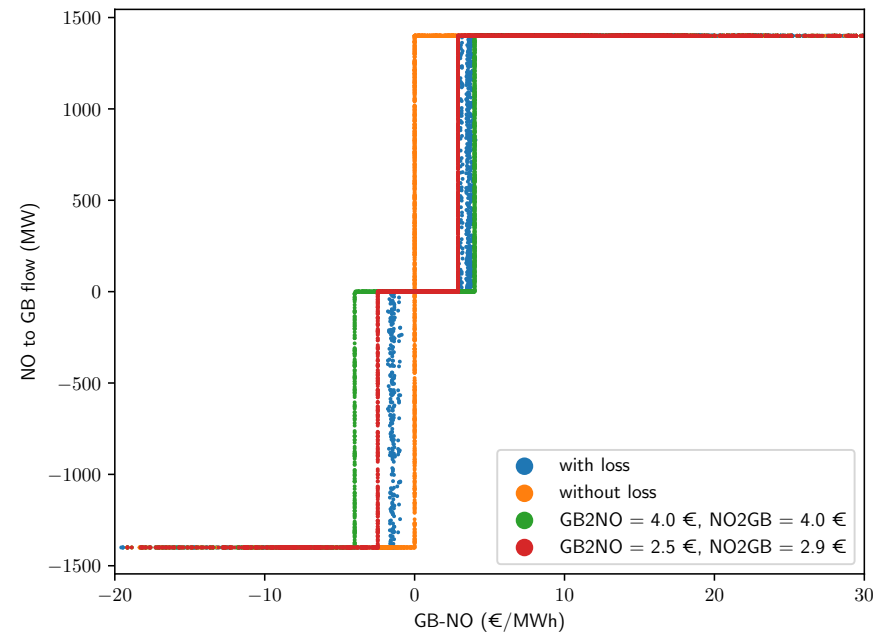

Fig. 6. A graph showing price difference vs flows on an interconnector between Great Britain and Norway. Four different cases of interconnction loss are considered.

TABLE III

VALUE OF MODELLING HVDC LOSSES ON UTILISATION AND AVERAGE PRICES

\begin{tabular}{lcccc}
\hline & & & \multicolumn{2}{c}{ Hurdle costs } \\
& w loss & wo loss & 4.0 & $\{2.5,2.9\}$ \\
\hline GB avg price & 58.83 & 57.73 & 57.86 & 57.83 \\
NO avg price & 49.96 & 50.00 & 49.94 & 49.95 \\
GB imports (TWh) & 9.64 & 10.33 & 9.25 & 9.54 \\
GB exports (TWh) & 1.02 & 1.29 & 0.89 & 1.01 \\
Utilisation (\%) & 87.17 & 95.04 & 82.9 & 86.33 \\
\hline
\end{tabular}

the choice of price background and generation merit order which determines the extent to which GB changes from a predominantly importing market to a more exporting market. Similarly, the impact of increasing interconnection capacity on carbon emissions is largely dependent on the choice of generation background and associated price assumptions. The results for 2020 show reduction of the GB carbon emissions in all the five scenarios, whereas in one of the scenario's the overall carbon emissions increased, which means that the GB thermal generation is being replaced by more carbon-intensive but cheaper thermal generation in Europe.

The paper also highlighted the impact of modelling losses. It is shown that modelling of losses is important to accurately model the utilisation of the links with significant potential to overestimate utilisation if losses are ignored. An important outcome is that the implied hurdle costs from explicitly modelling the losses are non uniform and can be asymmetrical depending on flow direction.

Increasing interconnection capacity increases competition, reduces market reserve requirements and facilitates utilisation of renewable energy sources. However, these benefits can only be achieved under efficient trading between markets. This paper has considered a model which assumes perfect foresight of electricity demand and generation availability. In reality, demand, generation availability and generation from renewable resources are subject to uncertainties. Furthermore, the interconnection trading takes place in stages involving forward contracts, bilateral trading, day-ahead market clearing and balancing. The decisions made in these stages influence the eventual flow of power on an interconnector. The different electricity market structures across interconnection may result in less than optimal utilisation of the links, as demonstrated in [17] for the interconnection between Ireland and Great Britain. However, further research is required to adequately capture the suboptimal behaviour of the trades that take place at different time periods between the European countries.

\section{ApPENDix A}

HURDLE COSTS

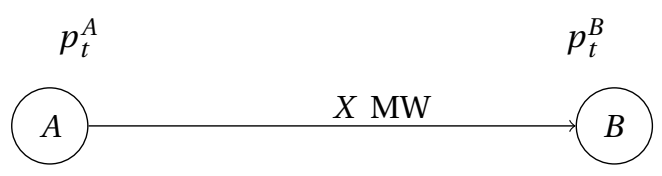

Fig. 7. An illustrative example of an HVDC link connection two electricity markets $\mathrm{A}$ and B. X MW is flowing from A to B. The prices are denoted by $p_{t}^{A}$ and $p_{t}^{B}$ during the time period $t$ in market $\mathrm{A}$ and $\mathrm{B}$, respectively.

Let $A$ and $B$ denote two electricity markets that are connected by an interconnector. Let $p_{t}^{A}$ and $p_{t}^{B}$ denotes the marginal price in market $\mathrm{A}$ and $\mathrm{B}$ at time period $t$, respectively. If $X \mathrm{MW}$ is flowing from market A to market $\mathrm{B}$, then according to the economic principles of power flowing from regions of the high price to low price the following inequality must hold:

$$
p_{t}^{A} X<p_{t}^{B} X\left(1-\frac{\lambda}{100}\right)
$$

where $\lambda$ is the percentage loss on the interconnector. Rearranging the above equation we have the following:

$$
p_{t}^{B}-p_{t}^{A} \geq \frac{\lambda p_{t}^{B}}{100}
$$

The inequality in (2) mean that the price difference between the two markets should atleast cover the cost of losses on the link. If the power is flowing from B to A, then we have the following:

$$
p_{t}^{A}-p_{t}^{B} \geq \frac{\lambda p_{t}^{A}}{100}
$$

The right hand sides of inequalities (2) and (3) are hurdle costs of power flowing from $\mathrm{A}$ to $\mathrm{B}$ and from $\mathrm{B}$ to $\mathrm{A}$, respectively.

The region of zero flows shown in Figure 6(a) is given by the following interval:

$$
\left[-\frac{\lambda p_{t}^{G B}}{100}, \frac{\lambda p_{t}^{N O}}{100}\right]
$$


where $p_{t}^{G B}$ and $p_{t}^{N O}$ are the marginal prices in GB and FR at time-perio $t$, respectively. The price in time period $t$ cannot be known apriori so in order to approximate the hurdle cost to be used in section IVC, we have used average marginal price in GB and NO.

$$
\begin{aligned}
& \text { Hurdle cost for GB to } \mathrm{NO}=\frac{58.83 \times 4.92}{100}=2.5 € / \mathrm{MWh} \\
& \text { Hurdle cost for NO to } \mathrm{GB}=\frac{49.96 \times 4.92}{100}=2.9 € / \mathrm{MWh}
\end{aligned}
$$

\section{REFERENCES}

[1] European Comission, "Scenario report, entso-e ten year network development plan," Tech. Rep., 2018. [Online]. Available: https://tyndp.entsoe.eu/

[2] European Commission, "Study on the benefits of additional electricity interconnections between iberian peninsula and rest of europe," 2016. [Online]. Available: https://publications.europa.eu/en/publication-detail//publication/2ad84365-3451-11e6-969e-01aa75ed71a1/language-en

[3] European Commission, "Towards a sustainable and integrated europe," Report of the Commission Expert Group on Electricity interconnection targets, Tech. Rep., 2017. [Online]. Available: https://ec.europa.eu/energy/sites/ener/files/documents/report_of_the _commission_expert_group_o n_electricity_interconnection_targets.pdf

$\begin{array}{lllll}\text { [4] Office of Gas and E. } & \text { M. } & \text { (Ofgem), } & \text { "Elec- } \\ \text { tricity interconnectors," } & \text { Tech. } & \text { Rep., } & 2018 . & \text { [On- }\end{array}$ line]. Available: https://www.ofgem.gov.uk/electricity/transmissionnetworks/electricity-interconnectors

[5] G. P. Swinand, A. Natraj, and A. O'Mahoney, "The european target model and the impact of implicit auctions on interconnection capacity prices," in 2016 13th International Conference on the European Energy Market (EEM), June 2016, pp. 1-6.

[6] Qiong Zhou and J. W. Bialek, "Approximate model of european interconnected system as a benchmark system to study effects of cross-border trades," IEEE Transactions on Power Systems, vol. 20, no. 2, pp. 782-788, May 2005.

[7] V. Di Cosmo, V. Bertsch, and P. Deane, "Impact of new interconnection lines on the eu electricity market," in 2016 13th International Conference on the European Energy Market (EEM), June 2016, pp. 15.

[8] M. Doquet, C. Fourment, and J. M. Roudergues, "Generation and transmission adequacy of large interconnected power systems: A contribution to the renewal of Monte-Carlo approaches," in 2011 IEEE Trondheim PowerTech, June 2011, pp. 1-6.

[9] K. Bruninx, Y. Dvorkin, E. Delarue, H. Pandzic, W. D'haeseleer, and D. S. Kirschen, "Coupling pumped hydro energy storage with unit commitment," IEEE Transactions on Sustainable Energy, vol. 7, no. 2, pp. 786-796, April 2016.

[10] Council of European Energy Regulators (CEER), "Ceer report on power losses," 2017. [Online]. Available: https://www.ceer.eu/documents/104400/-/-/09ecee88-e8773305-6767-e75404637087

[11] I. Staffell and S. Pfenninger, "Using bias-corrected reanalysis to simulate current and future wind power output," Energy, vol. 114, pp. $1224-1239,2016 . \quad$ [Online]. Available: http://www.sciencedirect.com/science/article/pii/S0360544216311811

[12] S. Pfenninger and I. Staffell, "Long-term patterns of european pv output using 30 years of validated hourly reanalysis and satellite data," Energy, vol. 114, pp. 1251 - 1265, 2016. [Online]. Available: http://www.sciencedirect.com/science/article/pii/S0360544216311744

[13] The Future of Carbon Pricing, "Implementing an independent carbon tax with dividends in the uk," Policy Exchange, Tech. Rep., 2018. [Online]. Available: https://policyexchange.org.uk/wpcontent/uploads/2018/07/The-Future-of-Carbon-Pricing.pdf

[14] W. Bukhsh and C. MacIver, "Supplementary data for the pscc 2020 paper: Assessing the value of increasing gb interconnection," Sep. 2019. [Online]. Available: https://doi.org/10.5281/zenodo.3463674
[15] F. Gaffney, J. Deane, S. Collins, and B. O. Gallachóir, "Consumption-based approach to res-e quantification: Insights from a pan-european case study," Energy Policy, vol. 112, pp. $291-300,2018 . \quad$ [Online]. Available: http://www.sciencedirect.com/science/article/pii/S0301421517306468

[16] S. Collins, D. Saygin, J. Deane, A. Miketa, L. Gutierrez, B. O. GallachÃşir, and D. Gielen, "Planning the european power sector transformation: The remap modelling framework and its insights," Energy Strategy Reviews, vol. 22, pp. $147-165,2018 . \quad$ [Online]. Available: http://www.sciencedirect.com/science/article/pii/S2211467X18300798

[17] I. V. Lytvyn and N. Hewitt, "Barriers to increased electricity interconnection between neighboring markets," in 2013 10th International Conference on the European Energy Market (EEM), May 2013, pp. 18. 